\title{
Simple technique to avoid inadvertent upside-down implantation of multipiece IOL with injector
}

\author{
Sudarshan Khokhar, Mousumi Banerjee (D) ,Amber Amar Bhayana (D) , \\ Vimal Vashistha
}

Dr Rajendra Prasad centre for Ophthalmic Sciences, AllMS, Delhi, Delhi, India

\section{Correspondence to} Dr Mousumi Banerjee; banerjeemou12@gmail.com

Accepted 9 January 2021

\section{DESCRIPTION}

The evolution of multipiece intraocular lenses (IOLs) has provided the option of sulcus implantation in situations wherein the bag implantation is not feasible. Multipiece IOLs are implanted in eyes with an intact anterior capsular rim and posterior capsular tear or with pre-existing posterior capsular defect.

Several cases have been described in the literature describing the upside-down implantation of three piece IOLs. ${ }^{1-4}$ Haptic angulation varying from 5 degrees to 10 degrees (based on the model of the lens) is present in a three piece lens leading to postoperative complications like iris chafing, pupillary block, pigment dispersion, iris transillumination defects, dysphotopsiae if implanted upside down.

Acrys of three piece IOL is a multi-piece lens with an overall length of $13 \mathrm{~mm}$ with haptics made of PMMA with an angulation of 10 degrees. The rigid poly methyl methacrylate (PMMA) haptics sometimes make it difficult to implant the IOL in proper configuration.

As the plunger is pushed, the multipiece IOL has a tendency to rotate inside the cartridge creating a torque. In order to overcome this problem, we have designed a technique of inserting these IOLs by rotation of the hand in order to nullify this torque.

Insertion of the multipiece should not be wound assisted. The cartridge tip has to go into the anterior chamber (AC).

A superior clear corneal incision is made using $3.2 \mathrm{~mm}$ keratome (figure $1 \mathrm{~A}$ ) after lensectomy and anterior vitrectomy (with pre-existing

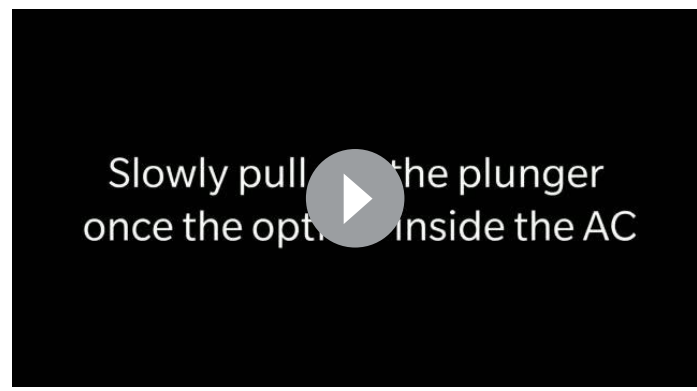

Video 1 Technique of multipiece intraocular lens insertion with injector with rotation of the hand to avoid inadvertent upside down implantation.

capsular defect) and a multipiece IOL was injected using Monarch injector system with a cartridge provided with the IOL.

Viscoelastic is put in the cartridge and the IOL is placed in it with its rear haptic placed on a hook at distal end of the cartridge. It is attached to the body of a Monarch injector and plunger is pushed forward. It should be noted that the plunger tip does not become entangled with the optic. Viscoelastic is injected into the anterior chamber and the cartridge tip is inserted into the anterior chamber through the corneal $3.2 \mathrm{~mm}$ keratome incision keeping the bevel downward (figure 1B). The bevel is turned to the left side of the surgeon by supination of the hand (figure 1C). The convexity of the haptic guides it either into the sulcus or into the bag as planned by the surgeon. Slow insertion of the lens is performed till the haptic optic junction reaches the tip of the cartridge (figure 1D). Slow pronation of the hand is performed with
Check for updates

(c) BMJ Publishing Group Limited 2021. No commercial re-use. See rights and permissions. Published by BMJ.

\footnotetext{
To cite: Khokhar $S$,

Banerjee M, Bhayana AA,

et al. BMJ Case Rep

2021;14:e241364.

doi:10.1136/bcr-2020-

241364
}
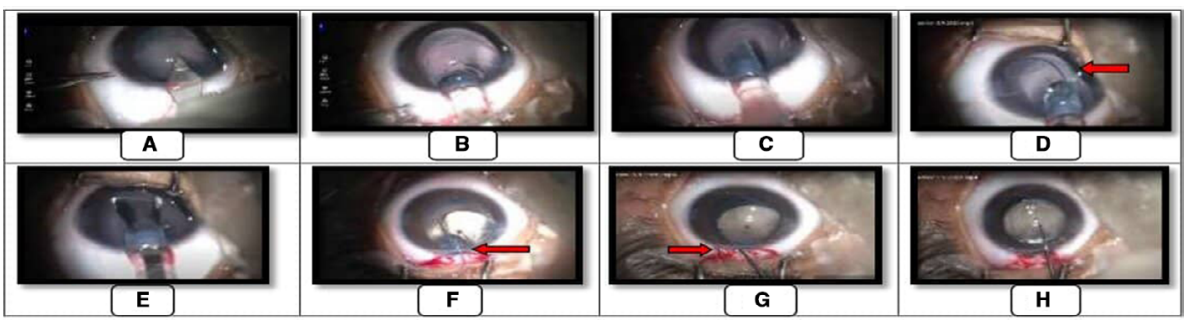

Figure 1 (A) Superior clear corneal incision is made using $3.2 \mathrm{~mm}$ keratome. (B) Cartridge tip is inserted into the anterior chamber through the corneal $3.2 \mathrm{~mm}$ keratome incision keeping the bevel downward. (C) The bevel is turned to the left side of the surgeon by supination of the hand. (D) Slow insertion of the lens is performed till the haptic optic junction reaches the tip of the cartridge. (E) Slow pronation of the hand is performed with the bevel facing downwards again, thus not letting the distal haptic to rotate. (F) The trailing haptic is at the incision site lying in the wrong orientation (which is correct for the technique as it reduces the chances of inadvertent rotation of the optic inside the eye).(G) The direction of the trailing haptic is corrected with the Sinskey hook. $(\mathrm{H})$ The trailing haptic is then dialled into the sulcus using Sinskey hook in clockwise direction. 


\section{Learning points}

- Upside-down implantation of the multipiece lens can lead to postoperative complications of glare, dysphotopsiae, pupillary block, iris chafing, elevated intraocular pressure.

- In spite of the above-mentioned knowledge, incorrect positioning of the lens has been reported in $1.3 \%$ of cases in most experienced hands.

- The authors emphasise the importance of nullifying the torque, which is created inside the cartridge by the multipiece intraocular lens as the plunger is depressed. This torque creates an increased propensity of inadvertent upside-down implantation of the lens inside the anterior chamber. Thus, our technique describes how to nullify the torque by rotation of the hand while inserting the lens.

the bevel facing downwards again, thus not letting the distal haptic rotate (figure $1 \mathrm{E}$ ). The plunger is slowly pulled out once the optic is inside the anterior chamber. The trailing haptic is at the incision site lying in the wrong orientation (which is correct for the technique as it reduces the chances of inadvertent rotation of the optic inside the eye) (figure $1 \mathrm{~F}$ ). The direction of the trailing haptic is corrected with the Sinskey hook (figure $1 \mathrm{G}$ ). The trailing haptic is then dialled into the sulcus using Sinskey hook in a clockwise direction (figure $1 \mathrm{H}$ ). The technique is illustrated step by step in video 1 .
Incorrect positioning of IOL in sulcus has been reported to occur in $1.3 \%$ of cases in most experienced hands. ${ }^{45}$ Thus, choosing the right lens and the right technique of insertion is of utmost important to avoid long-term complications.

Contributors $M B$ and $V V$ have worked up the case. $M B$ and $A A B$ have drafted the manuscript. SK has performed the surgery and edited the final manuscript.

Funding The authors have not declared a specific grant for this research from any funding agency in the public, commercial or not-for-profit sectors.

Competing interests None declared.

Patient consent for publication Obtained.

Provenance and peer review Not commissioned; externally peer reviewed.

\section{ORCID iDs}

Mousumi Banerjee http://orcid.org/0000-0003-4346-246X

Amber Amar Bhayana http://orcid.org/0000-0002-0770-601X

\section{REFERENCES}

1 Zhang X, Soni N, Alexander J, et al. Pupillary block due to reverse implantation of a sulcus intraocular lens. JCRS Online Case Rep 2016;4:41-4.

2 Harsum S, Low S. Reversed vaulted ACRYSOF intraocular lens presenting as pupillary block. Eye 2009;23:1880-2.

3 Halpern BL, Gallagher SP. Refractive error consequences of reversed-optic AMO SI40NB intraocular lens. Ophthalmology 1999;106:901-3.

4 Khng CYW, Yeo K-T. The IOL FLIP: rescue for foldable lens implantation gone wrong. $\mathrm{Br}$ J Ophthalmol 2003;87:656-7.

5 Khokhar S, Bhayana AA, Banerjee M, et al. In situ FLIP of a glistened upside down multipiece IOL to relieve pupillary block. BMJ Case Rep 2020;13:e239451.

Copyright 2021 BMJ Publishing Group. All rights reserved. For permission to reuse any of this content visit

https://www.bmj.com/company/products-services/rights-and-licensing/permissions/

BMJ Case Report Fellows may re-use this article for personal use and teaching without any further permission.

Become a Fellow of BMJ Case Reports today and you can:

- Submit as many cases as you like

- Enjoy fast sympathetic peer review and rapid publication of accepted articles

- Access all the published articles

- Re-use any of the published material for personal use and teaching without further permission

Customer Service

If you have any further queries about your subscription, please contact our customer services team on +44 (0) 2071111105 or via email at support@bmj.com.

Visit casereports.bmj.com for more articles like this and to become a Fellow 